\title{
Radiant Warmer Power and Body Size as Determinants of Insensible Water Loss in the Critically Ill Neonate
}

\author{
STEPHEN BAUMGART, ${ }^{(35)}$ WILLIAM D. ENGLE, WILLIAM W. FOX, and RICHARD A. POLIN \\ Division of Neonatology of The Children's Hospital of Philadelphia and the Department of Pediatrics, University of \\ Pennsylvania School of Medicine, Philadelphia, Pennsylvania, USA
}

\begin{abstract}
Summary
Twelve critically ill neonates mechanically ventilated for respiratory failure (mean weight $1.33 \mathrm{~kg}$, mean gestation 31 wk) were studied to quantitate the effects of radiant power from a radiant warming device, body weight, and body surface area on insensible water loss. Radiant power density $\left(\mathrm{Mw} / \mathrm{cm}^{2}\right)$ was measured using a wattmeter and thermopile transducer. Insensible water loss was measured using a Potter Baby Scale. Weight correlated inversely with insensible water loss, $(r=-0.86, P<0.001)$. Radiant power density correlated inversely to weight, $(r=-0.71, P<0.001)$. There was a significant increase in insensible water loss as radiant power density increased, $(r=0.54, P<0.05)$. Net radiant power received $(\mathrm{W} / \mathrm{kg})$ by infants over their exposed surface area, correlated directly to insensible water loss, $(r=0.67, P<0.01)$ irrespective of body weight. Critically ill neonates ventilated for respiratory failure and nursed under radiant warmers incurred greater insensible water losses than p-eviously reported for well infants. The magnitude of this increased insensible water loss is inversely related to body size and is dutermined directly by the radiant power density required to maintain body temperature.
\end{abstract}

\section{Speculation}

Quantitative measurement of radiant power density delivered to critically ill newborn infants nursed under servocontrolled radiant warmers facilitates estimation of insensible water loss. Used in conjunction with body mass and surface geometry, quantitative radiant power assessment is clinically applicable to monitoring insensible water loss. Calculation of parenteral fluid requirements might be enhanced using this technique.

Estimation of parenteral fluid requirements is an essential part of managing the critically ill newborn infant $(7,24,28)$. The current method of estimating fluid needs is based on replacement of measured urine volume plus insensible water loss $(7,24)$. Numerous factors are known to influence the magnitude of insensible water loss (28). Some of these factors include the infant's snvironment $(15,19)$, metabolic rate $(4,18,22,25)$, respiratory ate $(20,21)$ gestational maturity (13), body size (31), and surface area and proportion of body composition as water (13). Because $f$ the multiplicity of these factors, calculation of parenteral fluid :quirements is often a complex problem.

Another more recent concern in estimating parenteral fluid -quirements is the reevaluation of insensible water loss as influiced by advances in life support technology. The use of radiant Irmers and phototherapy may produce profound changes in id balance $(12,17,23,28,31)$. Moreover the advent of this hnology has allowed smaller and less mature infants to survive 37). The physiology of fluid homeostasis in these very low birth sight, critically ill infants is essentially unknown (24).

Inaccurate assessment of fluid requirements may result in a number of serious complications. Underestimation of fluid needs may lead to dehydration, hypotension, poor perfusion with acidosis, hypernatremia, and cardiovascular collapse $(6,9,30)$. Administration of excessive fluid has been implicated in the pathogenesis of pulmonary edema, congestive heart failure, opening of ductal shunts, and bronchopulmonary dsyplasia $(5,26)$.

Recent investigations have assessed insensible water loss in the newborn infant to provide better guidelines for parenteral fluid replacement. Bell et al. (3) and Marks et al. (19) have suggested that radiant energy received by these infants from radiant warmers and phototherapy may be one of several factors determining the magnitude of insensible water loss. Engle et al. (11) have quantitated radiant power delivered to critically ill infants and correlated this power to decreased urine output and increased urine concentration. However, there are little data on insensible water loss in very low birth weight infants ventilated for respiratory disease. It is this group of infants that is frequently nursed under radiant warmers and therefore is at highest risk for increased insensible water loss.

The purpose of this investigation is to demonstrate the degree to which insensible water loss is affected by body size and radiant warmer power delivery in low birth weight, critically ill neonates.

\section{MATERIALS AND METHODS}

Heat delivered by a radiant warmer (radiant power density), and insensible water loss were studied in 12 critically ill newborn infants (Table 1). Gestational ages of these infants ranged 25-36 wk, and weights ranged $0.67-2.10 \mathrm{~kg}$. Subjects were from 1 to 7 days of age at the time of study. Infants were nursed unclothed on radiant warmer beds (Air Shields, Infant Care System) servocontrolled by the infants' skin temperature to maintain axillary temperature within 36.5 to $37.2^{\circ} \mathrm{C}$. The ambient temperature of the intensive care nursery is maintained at $25^{\circ} \mathrm{C}$ and 40 to $45 \%$ relative humidity by a double walled construction and environmental control. Convective currents in the nursery occur as a result of movement of personnel, and from air ventilation ports located in the ceiling. No attempt was made to alter these conditions in order to study the environmental ambience as experienced by the infant. All infants were endotracheally intubated and were receiving a mixture of humidified oxygen and compressed air. Ten of the 12 infants were mechanically ventilated and two were receiving continuous positive airway pressure. Nine infants had respiratory distress syndrome and three were ventilated for apnea of prematurity. None of the infants was asphyxiated and all were stable at the time of study. Informed parental consent was obtained for all infants included in the study.

To determine the relationships between radiant power density, body weight, and insensible water loss, heat received by these infants was monitored by a radiant power monitoring technique previously described (1). As reported, a wattmeter (Ohio Semitronics, WM 1000) was connected between the radiant warmer 
Table 1. Patient data

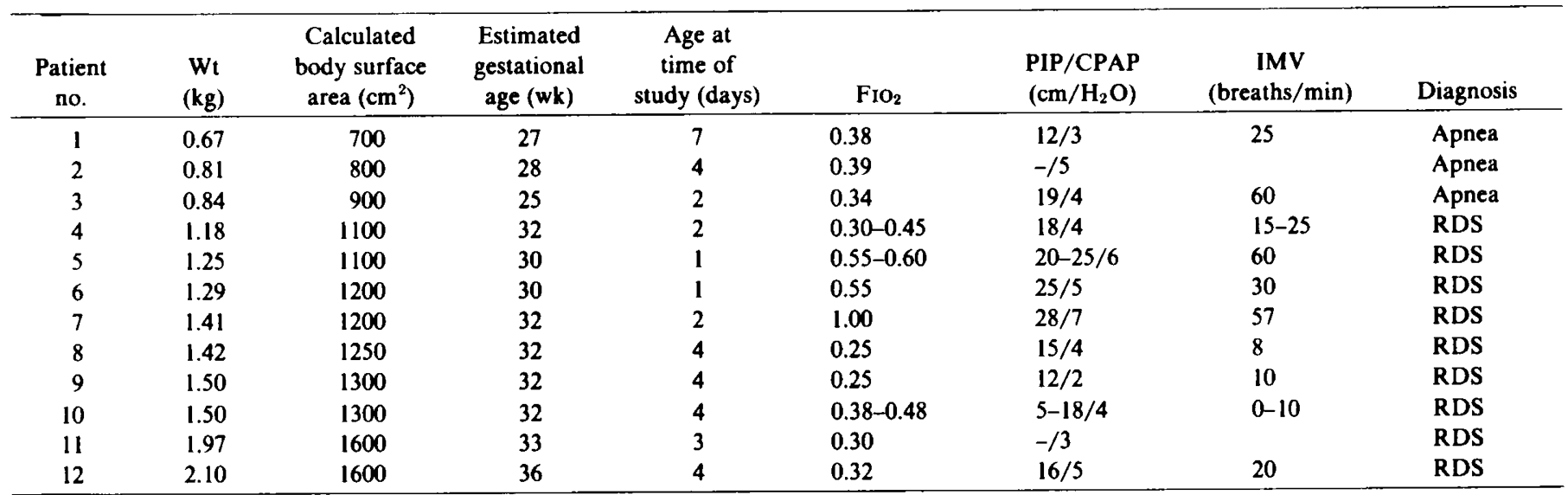

' RDS, respiratory distress syndrome; $\mathrm{FIO}_{2}$, fraction of inspired oxygen; PIP, peak inflating pressure; IMV, intermittent mechanical ventilation.

power cable and the electrical power outlet. Electrical power converted by the warmer into heat was measured in watts by the wattmeter. Heat received from the warmer by infants at bed level was measured with a thermopile transducer, (Eppley Model E6). Heat received was expressed as radiant power density in $\mathrm{Mw} / \mathrm{cm}^{2}$. We have previously reported a significant linear correlation $(r=$ $0.97, P<0.001, \mathrm{n}=53$ ) between electrical power used (watts), and power density received at bed level, $\left(\mathrm{Mw} / \mathrm{cm}^{2}\right)(2)$ :

$$
R P D=0.061(P)-2.611,
$$

Where, RPD = radiant power density measured by thermopile $\left(\mathrm{mw} / \mathrm{cm}^{2}\right) ; \mathbf{P}=$ Warmer power measured by wattmeter $(\mathrm{W})$. Continuous recording of wattmeter data on a polygraph (Hewlett Packard 47601A) was integrated and analyzed using this relationship to determine the mean radiant power density infants received over the study period.

As previously reported (13), insensible water loss was considered equal to insensible weight loss. An overestimation in water loss of 5-10\% may result since oxygen consumption and carbon dioxide production were not included in the calculation (Isenschmid equation) (16). Adaptation of the Potter Scale to weight determination in the intensive care setting was accomplished by amplifying the electronic signal output from the scale (Hewlett Packard 8802 Medium Gain Amplifier), and recording this signal onto a continuous polygraph tracing (12). To account for load drag on the scale all respiratory tubing, monitor leads, and intravenous lines were fixed securely both on and off the scale platform. Calibration of the scale was made by placing a $5 \mathrm{~g}$ Metler weight on the scale platform and noting the pen deviation on the polygraph. Accurate changes in weight over the study time were detectable with as little as $0.2 \mathrm{~g}$ weight change. Calibration was checked at the end of a study. Replicability of one hour weight determinations was established by measuring 2 consecutive hr in eight infants and comparing results from each hour with an independent Student's $t$ test. Measurements were not significantly different $(P=0.87)$. Respiratory gas mixtures were humidified using a Mistogen $\mathrm{Hu}$ midifer. Condensation on respiratory tubing was trapped prior to the scale apparatus. The humidifier was adjusted so that there was no vapor condensation on the tubing after the trap. In vitro study showed that when there was no visible condensation on the tubing from the point of fixture to the warmer bed to the endotracheal tube adaptor, there was no significant effect on scale function. Parenteral fluid intake was measured and included in the calculation of net insensible weight loss. Stool and urine were collected immediately and the scale was rezeroed on the polygraph. Artifact produced in the weight tracing by collection of urine and stool was deleted in analyzing insensible weight loss data.

Interrelationship of infant body weight, insensible water loss, and radiant power density was examined statistically using linear regression analysis $(10)$.

To establish the relative importance of radiant power density as an independent determinant of insensible water loss, the net radiant power received for each infant was calculated according to the following equation. (see Appendix):

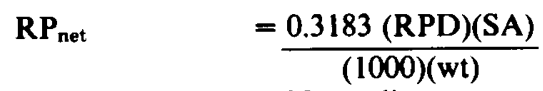

Where, $R P_{\text {net }} \quad=$ Net radiant power received by an infant over the portion of his body exposed to the radiant warmer, $(\mathrm{W} / \mathbf{k g})$.

RPD, (radiant = Radiant power received by an infant per $\mathrm{cm}^{2}$ power density) of body surface area, $\left(\mathrm{Mw} / \mathrm{cm}^{2}\right)$. When divided by 1000 , the unit $\mathrm{mw}$ is converted to watts.

SA $\quad$ = Body surface area calculated from weight and length using a neonatal nomogram, $\left(\mathrm{cm}^{2}\right)$ (14). This value adjusted by 0.3183 correlation factor for projection of RPD onto a curved surface.

Wt $\quad$ = Body weight $(\mathrm{kg})$.

Net radiant power represents only the amount of heat delivered to the skin of the infant and does not characterize the quantity of energy assimilated by the baby since this equation does not consider the contour and heat absorption characteristics of an infant's skin which may cause a portion of the incident radiant energy to be reflected. Net radiant power received from the radiant warmer was correlated to insensible water loss using linear regression analysis and the interrelationship of body weight, net radiant power received and insensible water loss was examined using linear regression analysis.

Study periods for these measurements were one hour in duration and were separated by one to $25 \mathrm{hr}$.

\section{RESULTS}

A total of 20 one-hr determinations was made. Six infants were monitored for one study period, four infants were monitored twice and two infants were studied on three separate occasions. The relationship of body weight and insensible water loss is shown in Figure 1. A significant negative linear correlation was found between body weight and insensible water loss, $(\mathrm{r}=-0.86, P<$ 0.001 ). This graph shows that very low birth weight infants (infants 0.67 to $0.89 \mathrm{~kg}$ ) incurred the highest insensible water loss, from 3.75 to $6.70 \mathrm{ml} / \mathrm{kg} / \mathrm{hr}$. Middle weight range infants $(0.90$ to 1.50 $\mathrm{kg}$ ) varied in insensible water loss from 1.15 to $3.95 \mathrm{ml} / \mathrm{kg} / \mathrm{hr}$. Little overlap occurred between the middle weight range and the very low birthweight infants. The larger and more mature infants (infants greater than $1.50 \mathrm{~kg}$ ) had the lowest measured losses, from 0.51 to $0.60 \mathrm{ml} / \mathrm{kg} / \mathrm{hr}$. No overlap occurred between this group and the middle range of infants. The very low birthweight infants had the greatest variability in insensible water loss.

Figure 2 demonstrates that a significant negative linear relationship was found betwen body weight and radiant power den- 


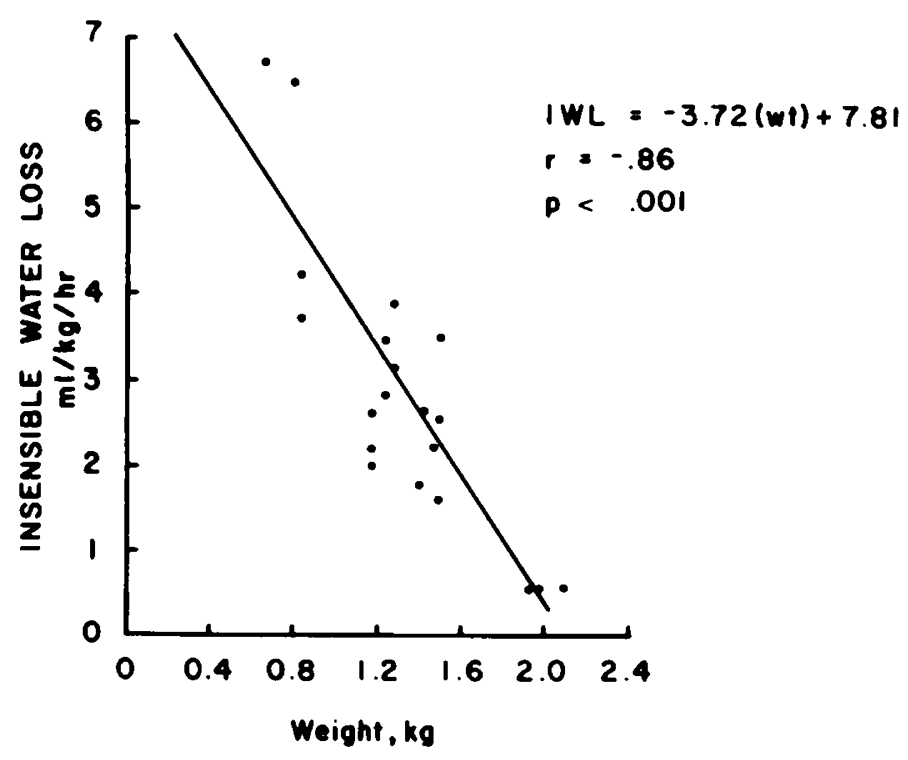

Fig. 1. Insensible water loss versus body weight in 12 critically ill neonates nursed under radiant warmers.

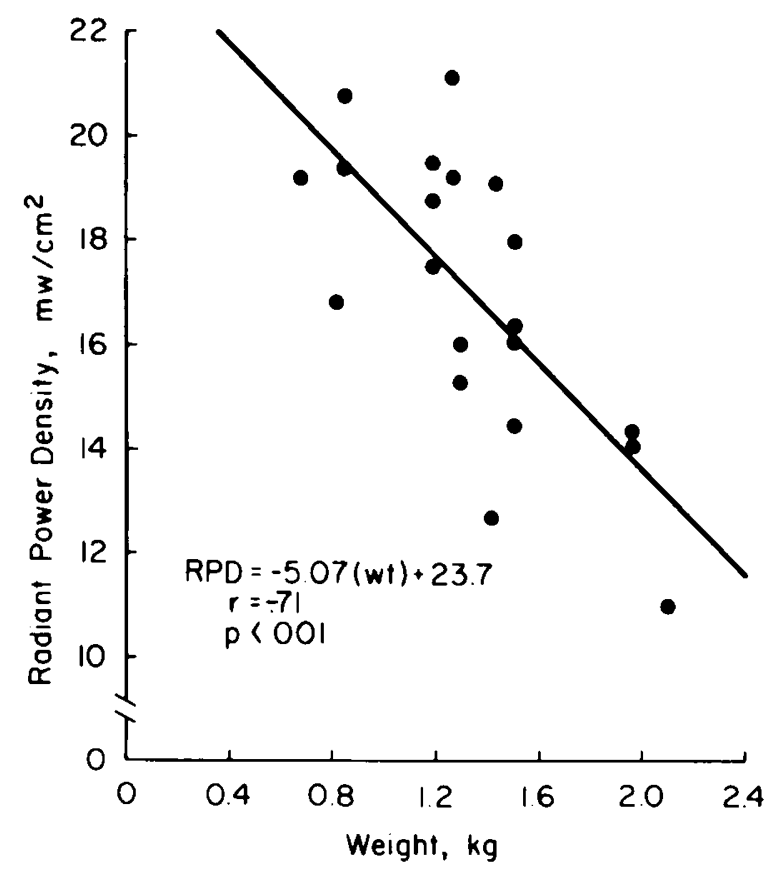

Fig. 2. Radiant warmer power density versus body weight in 12 critically ill neonates.

sity, (r $=-0.71, P<0.001)$. This graph shows more overlap in radiant power density received between the very low birth weight, the middle weight range, and the larger infants. As shown, infants in the middle weight group demonstrated heat demands occasionally in excess of the very low birth weight infants, $(12.7$ to 21.1 $\mathrm{Mw} / \mathrm{cm}^{2}$ for the middle weight range and 16.8 to $20.8 \mathrm{Mw} / \mathrm{cm}^{2}$ for the very low birth weight infants).

A positive linear correlation between radiant power density and insensible water loss is demonstrated in Figure 3, $(r=0.54, P<$ 0.05 ). There was more variability in insensible water loss at relative high radiant power densities than at the lower end of the radiant power scale. For example, in the 16.1 to $21.0 \mathrm{Mw} / \mathrm{cm}^{2}$ radiant power density range, insensible water loss ranged from 1.59 to $6.70 \mathrm{ml} / \mathrm{kr} / \mathrm{hr}$ while in the 11.0 to $16.0 \mathrm{Mw} / \mathrm{cm}^{2}$ range, insensible loss varied from only 0.51 to $3.90 \mathrm{ml} / \mathrm{kg} / \mathrm{hr}$. In general the largest insensible water losses occurred when radiant power densities were greater than $16.0 \mathrm{Mw} / \mathrm{cm}^{2}$.

The interrelationship of infant body weight (wt), insensible water loss (IWL) and radiant power density (RPD) is described by the equation:

IWL $=-4.20(\mathrm{wt})-0.09(\mathrm{RPD})+10.05$,

$$
\text { ( } \mathrm{r}=0.90, P<0.001) \text {. }
$$

To establish the relative importance of radiant power density as an independent determinant of insensible water loss, the net radiant power received per $\mathrm{kg}$ is plotted against insensible water loss in Figure 4. A significant positive linear correlation was demonstrated, $(r=0.67, P<0.01)$. Figure 4 shows that insensible water loss increased with the net radiant power delivered to the infants in this series irrespective of differences in surface area and body mass. Increased variability in insensible water loss is again

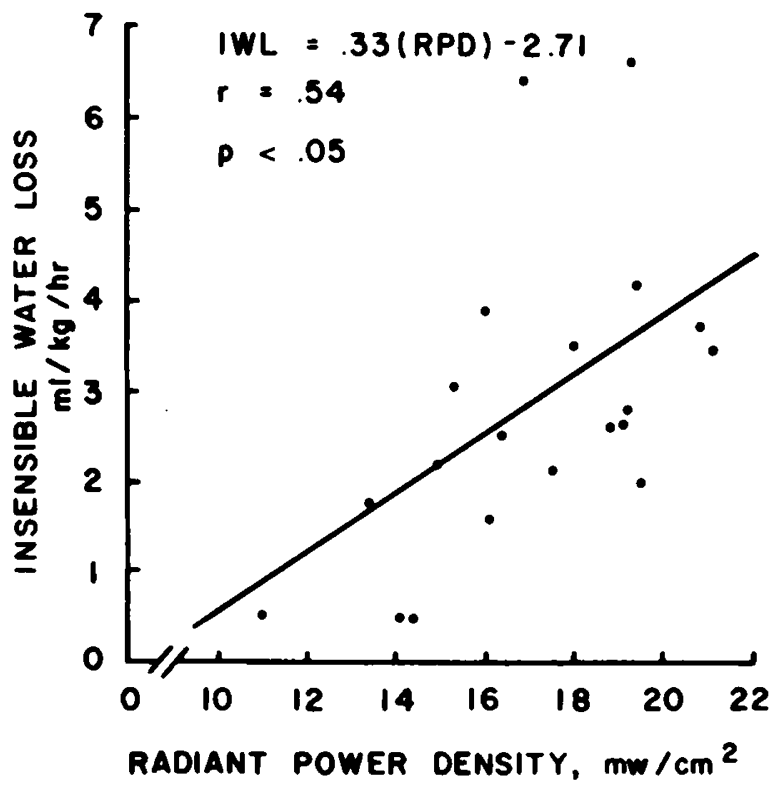

Fig. 3. Insensible water loss versus radiant warmer power density in 12 critically ill neonates.

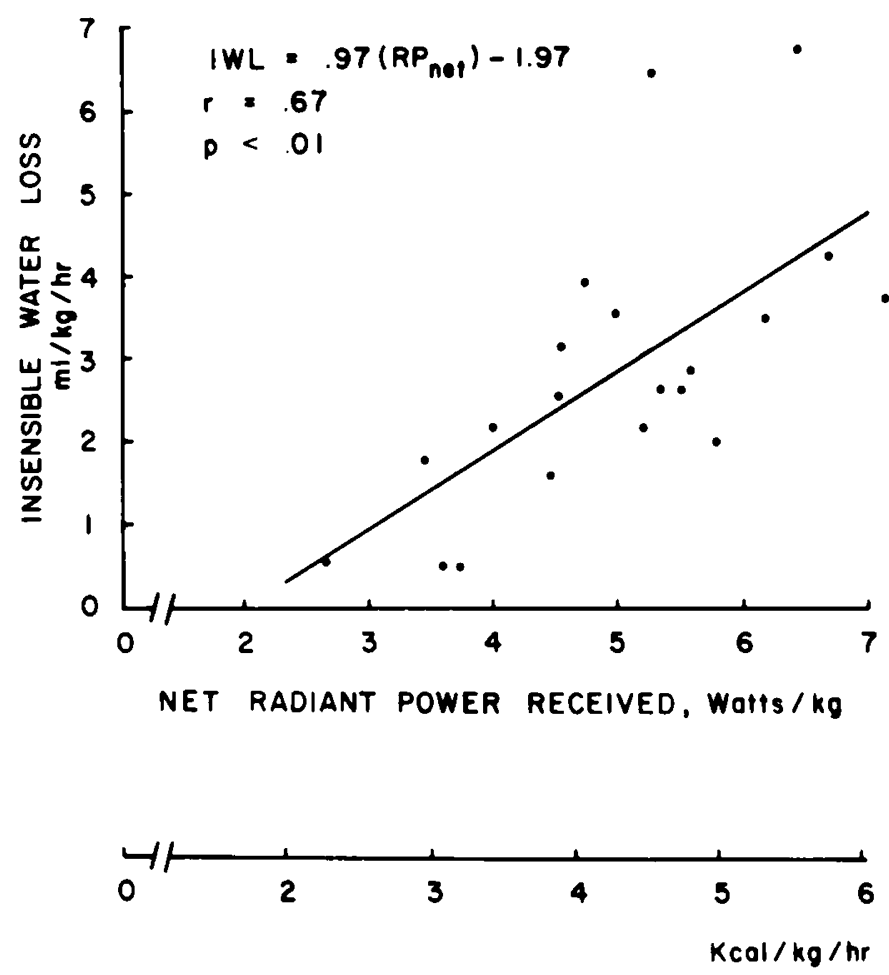

Fig. 4. Insensible water loss as a function of net radiant power received from a warmer bed in 12 critically ill neonates. 
observed in the higher heat regions of the curve. In general, insensible water loss increased with increased radiant power delivery independent of body weight and surface area.

The relationship of infant body weight (wt), insensible water loss (IWL) and net radiant power received $\left(R P_{\text {net }}\right)$ is described by the equation:

$$
\begin{array}{r}
I W L=-4.60(w t)-0.34\left(R P_{\text {net }}\right)+10.68 \\
\quad(r=0.87, P<0.001) .
\end{array}
$$

\section{DISCUSSION}

These data demonstrate that insensible water loss in critically ill infants nursed under radiant warmers correlates to infant body weight, surface area, and the radiant power density received from the radiant warmer device. Smaller infants require more radiant power density to maintain body temperature and they incur much greater insensible water loss when compared to larger, more mature infants. Moreover, the net radiant power received is an independent determinant of insensible water loss irrespective of body size and surface area.

Several studies to date have demonstrated that smaller premature infants have greater insensible water loss when compared to larger, more mature infants. Wu and Hodgman (32) determined that the mean insensible water loss in healthy premature infants nursed under radiant warmers was $2.54 \mathrm{ml} / \mathrm{kg} / \mathrm{hr}$ for infants less than $1.50 \mathrm{~kg}$, and $1.49 \mathrm{ml} / \mathrm{kg} / \mathrm{hr}$ for infants greater than $1.50 \mathrm{~kg}$. Yeh et al. (33) reported comparable values for healthy premature infants. They found insensible water loss was $2.56 \mathrm{ml} / \mathrm{kg} / \mathrm{hr}$ in infants less than $1.25 \mathrm{~kg}$ and $2.07 \mathrm{ml} / \mathrm{kg} / \mathrm{hr}$ in infants greater than $1.25 \mathrm{~kg}$. More recently Bell et al. (3) reported $2.43 \mathrm{ml} / \mathrm{kg} / \mathrm{hr}$ mean insensible water loss in a group of healthy premature infants whose mean weight was $1.24 \mathrm{~kg}$. The magnitude of the difference in insensible water loss between smaller and larger infants seems in part determined by the difference in weight between the two groups. Moreover the value for insensible water loss reported for the smallest group (less than $1.25 \mathrm{~kg}$ ) was 1.7 times larger than that reported for the largest group, (greater than 1.50).

In contrast the critically ill and very low birth weight infants studied in this series were found to have nearly a threefold increase in insensible water loss when compared to previous experience. One possible explanation for this large increase in insensible water loss is that transcutaneous evaporation is markedly increased in these infants. The substantial rise in insensible water loss may be attributed to surface geometry since body surface area to body mass ratio increases geometrically with decreasing weight. The observed linear increase in radiant power density required to warm the smaller infant's mass can also be explained by surface characteristics. The power density is distributed over the entire exposed surface of the infant, and therefore a larger body mass may be warmed by a linear increase in radiant power density. It can be concluded that infant weight and surface area are major factors in determining the amount of radiant power density required and the insensible water loss incurred. A second explanation for the large increase in insensible water loss in the very low birth weight, critically ill infant is that mechanical ventilation with humidified air may increase the respiratory component of insensible water loss. Data in adults demonstrate little effect of ventilation with a saturated gas mixture at body temperature on net water exchange (8). Mechanical ventilation in infants employs humidified gas mixtures which deliver nearly $100 \%$ relative humidity at 30 to $32^{\circ} \mathrm{C}$ to the endotracheal airway. The warmer, better humidified gas mixture used by the critically ill infant receiving mechanical ventilation should reduce, not increase the respiratory component of insensible water loss. Partition of insensible water loss into respiratory and transcutaneous losses was not done in this study, however, and care should be taken in comparing these data with data obtained in non-ventilated newborns. Finally the severity of illness in these patients may have contributed to the dramatic increase in insensible water loss when compared to previous studies. We were unable to evaluate severity of illness as an independent variable due to the relatively small number of patients studied.

This study also demonstrates that net radiant power received under a warmer is a determinant of insensible water loss independent of surface area or body mass. This observation is in agreement with a study by Engle et al. (11) which demonstrated increased urine concentration and a trend toward increased serum osmolality during periods of high radiant power density versus periods of low radiant power density. These authors attributed this observation to a renal response to increased insensible water loss by conservation of free water. Furthermore, Bell et al. (3) compared insensible water losses in infants nursed by radiant warmers under three phototherapy conditions. Though radiant power density delivered to these infants was not measured, the authors speculated that radiant energy may have been an important variable in determining the magnitude of the observed increased fluid loss.

These two previous studies suggest that an increase in net radiant power received from a warmer may result in a predictable increase in transcutaneous water loss. The present study supports this hypothesis since increased radiant power density correlated to an increase in insensible water loss. In addition smaller infants required more heat to maintain body temperature and incurred larger insensible water loss. In separating the two dependent variables of body weight and radiant power density, infant surface area and body mass were considered. The calculation of net radiant power received expresses radiant power density as total heat received per $\mathrm{kg}$ of body weight. This method does not control for other individual differences, for example thickness of skin or skin bloodflow. Moreover the net radiant power assimilated by the infant versus the amount of heat reflected by the skin was not determined. However, these results suggest that net radiant power received does result in a predictable amount of insensible water loss independent of body weight and surface area. Further investigation of radiant power fluctuation and simultaneous measurement of insesible water loss is required to demonstrate that fluctuation in power density causes changes in insensible water loss.

In summary, precise guidelines for replacement of urine and insensible fluid losses are required to achieve optimal parenteral fluid therapy in the critically ill neonate. This study demonstrates that radiant power density and body size are independent and significant determinants of insensible water loss. Frequent reassessment of parenteral fluid therapy and ongoing measurement of radiant power density will permit finer control of fluid balance in the critically ill newborn.

\section{APPENDIX}

Net radiant power density received $\left(R_{P_{n e t}}\right)$ is calculated to characterize the amount of heat an infant requires from the servocontrolled radiant warmer to maintain each unit of body mass at a constant temperature. The purpose of this calculation is to distribute the measurement of radiant power density $\left(\mathrm{Mw} / \mathrm{cm}^{2}\right)$ over the exposed body surface area of an infant $\left(\mathrm{cm}^{2}\right)$, and to normalize this quantity of heat per $\mathrm{kg}$ of body weight so that larger infants may be compared to smaller infants. Several assumptions are made in deriving the formula for $\mathbf{R P}_{\text {net }}$.

First, the radiant device is assumed a plane heat source delivering a uniform radiant power density (RPD) to all portions of the surface of the bed irradiated. In vitro measurement of RPD over the entire bed's surface confirms this hypothesis (available on request).

Second, the portion of radiant power density interrupted by the infant's body constitutes a projection of the infant's silhouette onto a plane. The area of this irradiated silhouette is assumed to relate to the infant's body surface area. Empirical proof of this conjecture may be derived from the geometric model used by Haycock et al. (14) to derive body surface area. In this paper a series of cylinders was used to model an infant's limbs and torso. The surface area of the cylinder radius $r$ and length $L$ is $2 \pi \mathrm{rL}$. The area of the projection of this cylinder onto a plane parallel to $\mathrm{L}$ is a rectangle $2 \mathrm{rL}$. To derive the projected rectangle's area from 
the cylinder's surface area, the cylinder surface area may be divided by $\pi$. This relationship also holds for the sum of surface areas of a set of cylinders. Therefore, multiplying an infant's surface area by $1 / \pi(=0.3183)$, results in an estimate of the area of that infant's silhouette projected onto a plane. The portion of radiant power from the warmer that is interrupted by the baby corresponds to the power density $\left(\mathrm{Mw} / \mathrm{cm}^{2}\right)$ times this projected area $\left(\mathrm{cm}^{2}\right)$.

Finally, the formula for $\mathrm{RP}_{\text {net }}$ assumes no other sources of radiant heat. Justification for this assumption may be derived from the general equation for radiant heat transfer:

$$
\mathrm{Q}_{\mathrm{r}}=\mathrm{h}_{\mathrm{r}}\left(\mathrm{T}_{1}-\mathrm{T}_{2}\right)
$$

where $Q_{r}$ is the rate of radiant heat transfer; $h_{r}$ is a constant; $T_{l}$ and $T_{2}$ are mean surface temperatures (29). As demonstrated by this equation, the rate of heat transfer is determined solely by the magnitude of the difference in temperature between the two bodies involved. Since the difference in temperature between an infant's exposed skin and the surrounding walls and objects is much less than the difference in temperature between skin and the radiant warming device, net radiant heat transfer is probably greatest from the warmer to the infant. In vitro data confirms these observations (available on request). Therefore, the radiant warmer essentially dominates an infant's radiant environment.

$\mathrm{RP}_{\text {net }}$ may be expressed in $\mathrm{W} / \mathrm{kg}$ or in $\mathrm{kcal} / \mathrm{kg} / \mathrm{hr}$, since $1 \mathrm{~W}$ $=1 \mathrm{~J} / \mathrm{sec}$ and $1 \mathrm{kcal}=4.184 \mathrm{~kJ}$.

\section{REFERENCES AND NOTES}

I. Baumgart, S., Engle, W. D., Langman, C. B., Fox, W. W., and Polin, R. A.: Monitoring radiant power in the critically ill newborn under a radiant warmer. Crit. Care Med., 8: 721 (1980).

2. Baumgart, S., Engle. W. D., Langman, C. B., Fox, W. W., and Polin, R. A.: Radiant energy monitoring in the critically ill neonate. Clin. Res., 27: 823A (1979).

3. Bell, E. F., Neidich, G. A., Cashore, W. J., and Oh, W.: Combined effect of radiant warmer and phototherapy on insensible water loss in low-birth-weight infants. J. Pediatr., 94: 810 (1979).

4. Benedict, F.: The influence of inanition on metabolism. Washington, D.C.: Carnegie Institute Publication no. 77 (1970).

5. Brown, E. R., Stark, A., Sosenko, I., Lawson, E. E., and Avery, M. E.: Bronchopulmonary dysplasia: Possible relationship to pulmonary edema. J. Pediatr., 92: 982 (1978)

6. Dell, R. B.: Pathophysiology of dehydration. In: Winters, R. W.: The Body Fluids In Pediatrics. p. 134 Little Brown Co., Boston. (1973).

7. Drezer, $M$.: Fluid and electrolyte requirements in the newborn infant. Pediatr. Clin. N. Am., 24: 537 (1977).

8. Drey, R.: Water balance of the respiratory tract during ventilation with a gas mixture saturated at body temperature. Can. Anaesth. Soc. J., 20: 719 (1973).

9. Driscoll, J. M., and Heird, W. C.: Maintenance fluid therapy during the neonatal period. In: Winters, R. W.: The Body Fluids In Pediatrics. p. 265 (Little Brown Co., Boston, 1973).

10. Edwards, A. L.: An Introduction To Linear Regression and Correlation. p. 61 (W. H. Freeman and Co., San Francisco, 1976).

11. Engle. W. D., Baumgart, S., Fox, W. W., and Polin, R. A.: Effect of increased radiant warmer power on fluid balance in the critically ill neonate. Pediatr.
Res., 13: 494 (1979)

12. Engle, W. D., Baumgart, S., Schwartz J. G. Fox, W. W. and Polin, R. A Combined effect of radiant warmer power and phototherapy on insensible water loss in the critically ill neonate. Am. J. Dis. Child., 135: 516 (1981).

13. Fanaroff, A. A., Wald, M., Gruber, H. S., and Klaus, M. H.: Insensible water loss in low birthweight infants. Pediatrics, 50: 236 (1972).

14. Haycock. G. B., Schwartz, G. J., and Wisotsky, D. H.: Geometric method for measuring body surface area. A height-weight formula validated in infants, children and adults. J. Pediatr., 93: 62 (1978).

15. Hey, E. N., and Katz, G.: Evaporative water loss in the newborn baby. J. Physiol., 200: 605 (1969).

16. Isenschmid: Die bestimmung der wasserbilanz am kraukenbett. Med. Klin Berlin, 14: 1128 (1918).

17. Jones, R. W. A., Rochefort, M. J., and Baum, J. D.: Increased insensible water loss in newborn infants nursed under radiant heaters. Br. Med. J., 2: 1347 (1976).

18. Levine, S. Z., and Marples, E.: The insensible perspiration in infancy and in childhood: III. Basal metabolism and basal insensible perspiration of the normal infant: A statistical study of reliability and of correlation. Am. J. Dis Child., 40: 269 (1930).

19. Marks, K. H., Gunther, R. C., Rossi, J. A., and Maisels, M. J.: Oxygen consumption $\left(\mathrm{VO}_{2}\right)$ and insensible water loss (IWL) in premature infants under radiant heaters. Pediatr. Res., 13: 500 (1979).

20. O'Brien, D., Hansen. J. D. L., and Smith, C. A.: Effect of supersaturated atmospheres on insensible water loss in the newborn infant. Pediatrics. 13:126 (1954).

21. Oh, W., and Karecki, H.: Phototherapy and insensible water loss in the newborn infant. Am. J. Dis. Child., 124: 230 (1972)

22. Oh, W., Yao, A. C., Hanson, J. S., and Lind, J.: Peripheral circulatory response to phototherapy in newborn infants. Acta Paediat. Scand., 62: 49 (1973).

23. Okken, A., Jonxis, J. H., Rispens, P., and Zijlstra, W. G.: Insensible water loss and metabolic rate in low birthweight newborn infants. Pediatr. Res., 13: 1972 (1979).

24. Robinson, R. O., and Jones R.: Advantages and disadvantages of overhead radiant heaters. Proc. Royal Soc. Med., 70: 209 (1977).

25. Roy, R. N., and Sinclair, J. C.: Hydration of the low birth-weight infant. Clin Perinatol., 2: 393 (1975).

26. Soderstrom, G., and DuBois, E.: Water elimination through skin and respiratory passages in health and disease. Arch. Intern. Med., 19:931 (1917).

27. Stevenson, J. G.: Fluid administration in the association of patent ductus arteriosus complicating Respiratory Distress Syndrome. J. Pediatr., 90: 257 (1977)

28. Stewart, A. L., Turcan, D. M., Rawlings, G., and Reynolds, E. O. R.: Prognosis for infants weighing $1000 \mathrm{~g}$ or less at birth. Arch. Dis. Child., 52: 97 (1977).

29. Swyer, P. R.: Heat loss after birth. In: Sinclair, J. C.: Temperature Regulation and Energy Metabolism in the Newborn p. 94. (Grune \& Stratton. New York. 1978).

30. Williams, P. R., and Oh, W.: Effects of radiant warmer on insensible water loss in newborn infants. Am. J. Dis. Child., I28: 511 (1974).

31. Winters, R. W.: Maintenance fluid therapy. In: Winters, R. W.: The Body Fluids In Pediatrics. p. 113 (Little Brown Co., Boston, 1973).

32. Wu, P. Y. K., and Hodgman. J. E.: Insensible water loss in preterm infants Changes with postnatal development and non-ionizing radiant energy. Pediatrics, 54: 704 (1974).

33. Yeh, T. F., Amma, P., Lilien, L. D., Baccaro, M. M., Maywynshyn, J., Pyato. S., and Pildes, R. S.: Reduction of insensible water loss in premature infants under the radiant warmer. J. Pediatr., 94: 651 (1979).

34. The authors wish to acknowledge the nurses in the intensive care unit for their help in these clinical studies. They also wish to thank Barbara Erwins for editorial assistance and Jacob Schwartz for technical assistance.

35. Requests for reprints should be addressed to: Stephen Baumgart, M.D. Division of Neonatology, The Children's Hospital of Philadelphia, 34th Street \& Civic Center Boulevard, Philadelphia, PA 19104 (USA).

36. Received for publication March 15, 1980.

37. Accepted for publication April 16, 1981. 